\title{
Representação linguística: \\ perspectivas práticas e teóricas
}

Telma Pereira (UFF)

Débora Costa (UFF/CAPES)

\begin{abstract}
Resumo
Quando indagado sobre as razões para se estudar as representações sociais, Moscovici (2010) respondeu que era para explorar o lado subjetivo dos fatos da realidade objetiva. Neste artigo, propomos uma revisão bibliográfica acerca do conceito de representações linguísticas sob a perspectiva da sociolinguística, desde sua constituição, no âmbito da psicologia social, até sua aplicação aos estudos da linguagem. Ressaltamos aqui a noção de representação linguística como um conceito coletivamente construído acerca de uma língua, marcado tanto pela prática e pela memória discursiva de seus falantes quantopela ideologia na qual estão inseridos, ressaltando ainda sua importância para a análise das dinâmicas linguísticas.
\end{abstract}

Palavras-chave: Representação social; representação linguística; atitude linguística. 


\section{Introdução}

O estudo das representações linguísticas nos permite compreender a relação que os falantes estabelecem tanto com a própria língua quanto com outras línguas. A análise das representações linguísticas se apresenta, assim, como uma forte aliada para a compreensão de questões linguísticas envolvendo a regressão/ desaparecimento de uma língua, as políticas para revitalização de línguas, segurança/insegurança linguística, bem como as abordagens para o ensino de línguas. É importante salientar que uma representação favorável a respeito de uma determinada língua pode, por exemplo, fazer com que, em situações de contato linguístico, predomine o uso desta em detrimento de outra qualquer, ou que o seu ensino-aprendizado seja mais eficaz, podendo até mesmo interferir em uma dada política linguística.

Por definição, as representações linguîsticas não correspondem necessariamente a uma realidade objetiva, mas elas apontam na direção das práticas linguísticas, constituindo objetos discursivos, impregnados pelas condições nas quais foram produzidos. No âmbito dos estudos linguísticos, elas constituem um binômio interativo com as práticas linguísticas.

Para tanto, é preciso investigar como as representações se constituem? Como se transformam em senso comum? Como analisar as suas formações? Uma significação não é fixa, mas reconstrói-se através das interações humanas e pelos veículos de comunicação social.

Revisitamos neste trabalho o conceito de representação linguística e sua aplicação no campo dos estudos da linguagem no Brasil.

\section{Representação social e representação linguística}

A sociologia possui uma questão essencial que é entender como um grupo de indivíduos pode formar uma sociedade. Para analisar essa construção coletiva de significados, a psicologia social utilizou a noção de "representação social", que pode assumir várias formas, como o estereótipo, por exemplo. Uma visão estereotipada surge de uma formulação pré-construída, estocada na memória de uma comunidade.

A partir da psicologia social o conceito de representação social ganha uma teorização a partir dos trabalhos de Serge Moscovici, e aprofundada por Denise Jodelet (2001). Em sua obra La Psychanalyse, sonimage, sonpublic, publicada em 1961, Moscovici reformula o conceito de "representação coletiva", proposto por Durkheim (1973), e apresenta a formação das representações como um processo fruto das interações socioculturais.

Moscovici (2010, p. 29) estabelece três grandes planos na gênese das representações sociais: o plano individual, o plano interindividual e o plano social. Assim, segundo Moscovici (1961), as representações sociais possuem três dimensões : um nível de informação que o indivíduo possui no interior de seu(s) grupo(s) à respeito de um dado objeto,uma dimensão estrutural que são as 
formas pelas quais as representações são organizadas e uma dimensão atitudinal, que é uma forma avaliativa em relação ao objeto da representação. Para esse autor, as representações são passarelas entre o mundo individual e o mundo social.

Quando confrontado com o real, o sujeito o reconstrói, remodela mentalmente esse objeto, categorizando suas informações, dando à realidade uma significação concreta. Essa transmissão se dá em um grupamento social, sendo essencial à comunicação entre os membros do grupo assegurando uma conivência inicial, que não precisa ser reconstruída a todo momento (CAVALLI; COLETTA, 2003, p. 17).

Os estudos que levam em conta indivíduos, línguas e seu uso tiveram início nos anos de 1960, sob a ótica da atitude linguística. Esta é definida como uma disposição a reagir de maneira favorável ou não a um dado objeto, no caso, a uma língua. Especialistas em aprendizagem têm a representação como um conceito fundamental e, por isso, aprofundam esta noção para uma perspectiva didática.

O fato é que a noção de representação está cada vez mais ligada aos estudos linguísticos, tratando da representação que os locutores fazem acerca das línguas, de suas normas, de suas características, ou de seus status face às outras línguas, influenciando as estratégias que envolvem o uso e o aprendizado. (CASTELLOTTI; MOORE, 2002, p. 9).

A adoção do conceito de representação pelo viés da linguística ocorreu, principalmente, a partir dos trabalhos de Wallace Lambert e de seu grupo de colaboradores, em 1960. O estudo desenvolvido no âmbito da psicologia. $\mathrm{O}$ trabalho desenvolvido por esse grupo tinha como objetivo medir o status das línguas inglesa e francesa, em Montreal, no Canadá. Para esse trabalho, eles desenvolveram uma técnica largamente utilizada e adaptada até hoje nos estudos envolvendo atitude e representação linguística: a técnica do matched-guise.

A técnica do matched-guise consistia em pedir que os sujeitos escutassem uma gravação com falantes dessas línguas. Em seguida, perguntava-se a esses sujeitos o que eles achavam das pessoas que tinham escutado na gravação e solicitava-se que os sujeitos avaliassem essas pessoas através do uso de adjetivos como "educado", "ambicioso" "gentil" ou "solidário". Os resultados dessa pesquisa mostraram que tanto os falantes de inglês como de francês não tinha uma imagem positiva dos francófonos.

Ao comentar essa técnica, Fasold (1984, p. 158) destaca as seguintes contribuições dos estudos sobre atitudes linguísticas: a importância social da linguagem; contribui para a definição de uma comunidade de fala e para a explicação da mudança e manutenção linguística; atua nas questões aplicadas ao campo da comunicação intergrupo, planejamento linguístico e educação. 
Posteriormente, utilizando a mesma técnica, Anisfeld e Lambert (1964) realizaram uma pesquisa sobre a atitude linguística das crianças em Montreal. A conclusão foi que as crianças bilíngues possuíam menos estereótipos que as crianças monolíngues em relação aos falantes do inglês e do francês. Além disso, em relação ao grupo linguístico ao qual pertenciam, as crianças demonstraram possuir uma avaliação mais positiva que aquela expressa pelos adultos.

A construção das representações linguísticas ocorre geralmente em uma matriz ideológica cujo modelo pode determinar, por exemplo, uma variante linguística como legítima, ou privilegiar um dialeto dotando a variante regional de um status superior aos das demais variantes, ou ainda basear-se na ideologia do monolinguismo, calcado na fórmula uma língua/uma nação, que caracterizou políticas linguísticas de vários países, inclusive o Brasil, em sua relação com as línguas indígenas e as línguas dos imigrantes que aqui se estabeleceram como nos mostram os trabalhos de Mariani (2004), Oliveira (2003), entre outros.

\section{Atitudes ou representação}

Muitos autores, como Dominique Lafontaine (1997), CécileCanut (1998) e Marie-Louise Moreau (1997), procuram distinguir os conceitos de atitude, de imaginário e de representação linguística. É consenso entre os linguistas a definição de atitude linguística como a manifestação de preferências e convenções sociais acerca do status e prestígio de seus usuários. Geralmente, os grupos sociais de maior prestígio social norteiam as atitudes linguísticas das comunidades de fala. Segundo Moreno Fernández (1998, p. 179), a atitude linguística é a manifestação da atitude social dos indivíduos, identificada por centrar-se e referir-se tanto à língua como ao uso que dela se faz em sociedade.

Em seu estudo sobre manutenção e mudança linguísticas Fishman (1995) aponta três categorias básicas de atitudes linguísticas: condutas de atitude afetiva (lealdade, antipatia...), atuação condutiva explícita (controle e regularização do uso de hábitos linguísticos mediante o reforço, a planificação, a proibição...) e as condutas cognitivas (consciência linguística, conhecimento linguístico, percepções grupais relacionadas com a língua...). Essas categorias servem para definir a atitude dos sujeitos diante das línguas.

Houdebine-Gravaud (2008) ao tratar do conceito de imaginários linguísticos discute a ideia de sentimentos linguísticos sobre as línguas, sobre a valorização e a desvalorização das formas linguísticas, sem negligenciar a relação das representações com as práticas linguísticas.

Calvet (2000, p. 158) propõe diferentes categorias para tratar da representação: práticas e representações, em que as práticas representam o que os locutores produzem, enquanto as represen- 
tações dizem respeito ao modo com que os falantes pensam as suas práticas, como eles se situam em relação aos demais. Para o autor, as representações estariam mais ligadas às funções desempenhadas pelas línguas. No entanto, o autor não estabelece uma diferença marcante entre os conceitos de representação e de atitude linguística.

Brunetiere e Guellouz (2008, p. 7-9) afirmam que o modelo do imaginário linguístico permite a classificação e a hierarquização dos discursos a respeito da língua, através de diferentes categorias, denominadas normas. As normas subjetivas são, de fato, o local onde se encontra o imaginário linguístico. Entre ficção e prescrição, os sujeitos revelam, por meio da linguagem, suas relações com a língua e o mundo. Ainda de acordo com os autores, as mudanças discursivas, operadas pelas mudanças sociopolíticas, determinam as visões que temos do mundo. Nesse sentido, uma representação social típica apontada por Bagno (1999) é que há uma língua portuguesa autêntica, pura, e que no Brasil só se fala essa língua. $O$ domínio ou não da norma culta aparece diretamente relacionado ao prestígio ou ao desprestígio linguístico. A ideia em questão está fortemente enraizada nos sistemas educacionais e no senso comum dos brasileiros, mas é ideologicamente construída. Essas asserções são profundamente apoiadas em representações linguísticas.

Houdebine-Gravaud (2008, p. 17-19) salienta que todo o reencontro de um falante com a sua própria fala, com a sua língua, é difícil, inseguro e de culpa. Para a linguista, esse fato aponta para diversas questões de investigação: os fenômenos são de que ordem? Atitude, representação, sentimento, afeto... Que incidência eles podem ter sobre a fala do sujeito? Eles afetam globalmente o seu discurso, agindo na sua e nas outras línguas, ou apenas em certos níveis, como pronúncia, vocabulário? Que influências podem ter sobre a dinâmica linguística ou sobre idiomas diversos?

Na relação entre representação e prática, não sabemos quem influencia mais a outra, mas sabemos que estão em constante interação. Petitjean (2009, p. 60) define a representação linguística como uma representação social da língua relacionada a um conjunto de conhecimentos não científicos, socialmente elaborados e compartilhados. A autora observa dois níveis de representação linguística: um exterior à língua (a representação do falante em relação à uma outra língua), e outro interno (a representação do falante em relação à sua própria língua).

O trabalho da linguista CécilePetitjean (2009) é atualmente um dos mais completos no que concerne à definição do conceito de representação linguística. A autora faz um extenso trabalho acerca dos temas congêneres à representação para, em seguida, abordar uma situação de plurilinguismo em duas comunidades francófonas na periferia das cidades de Marseille, na França, e de Lausane, na Suíça. 
No Brasil, ao realizarmos uma busca virtual nos bancos de teses e dissertações, observamos que o termo atitude recobre mais os estudos que tratam da representação linguística no sentido dado pela psicologia social e pela sociolinguística europeia.

No próximo tópico, selecionamos alguns trabalhos na área de contato linguístico, ensino de línguas e de política linguística para ilustrar a importância e aplicabilidade do conceito de representação linguística. Veremos que muitos desses autores também estipulam uma separação rígida entre atitude e representação.

\section{Observando a realidade objetiva}

Quando indagado sobre as razões para se estudar as representações sociais, Moscovici respondeu que era para explorar o lado subjetivo dos fatos da realidade objetiva. Atualmente, representação linguística e atitude linguística são palavras-chave recorrentes em inúmeros trabalhos na área da sociolinguística no Brasil, sobretudo a partir do século XXI.

Observamos que, ao analisar as representações, esses trabalhos apontaram a necessidade em aprofundar questões tais como: políticas linguísticas, preconceito linguístico, identidade linguística, revitalização linguística, entre outros. Observamos que o interesse por tais questões derivaram, frequentemente, dos trabalhos de campo realizados para coleta de dados.

Nesses trabalhos, como fundamentação teórica em comum, ressaltamos os nomes dos seguintes autores: Serge Moscovici, Joshua Fishman, Wallace Lambert, WilliamLabov, Pierre Bourdieu, Louis-Jean Calvet. Quanto à metodologia adotada por essas pesquisas, a grande maioria é predominantemente qualitativa de cunho etnográfico, e utiliza como instrumentos de pesquisas na coleta de dados a técnica do matched-guise, desenvolvida por Lambert (1966), além da aplicação de questionário e de entrevistas.

Figueiredo (2003) lança mão da técnica do matched-guise, desenvolvida por Lambert em pesquisas sobre atitudes linguísticas no Canadá, e a utiliza para analisar as atitudes de um grupo de estudantes brasileiros de ensino médio com relação a falantes de alemão, inglês, espanhol, francês e português. Os resultados dessa pesquisa sugerem que todas as línguas estrangeiras pesquisadas neste estudo tiveram uma avaliação mais alta em termos de status e solidariedade em comparação ao idioma português.

Partindo do pressuposto que, além da variedade linguística, diferenças culturais justificam as maneiras de socialização dos grupos que investigou, Barbosa (2004) investigou as atitudes linguísticas de brasileiros e colombianos bilíngues em português e em espanhol, habitantes da região urbana de Tabatinga, no lado brasileiro, e de Letícia, no lado colombiano. Segundo a autora, as atitudes estudadas referem-se basicamente ao sentido de estética de cada idioma; à importância que possuem essas línguas para 
os sujeitos de cada nacionalidade; à preferência que cada grupo nacional expressa sobre o português e o espanhol e à consciência sobre quem fala melhor.

Bergamaschi (2006) investigou as atitudes linguísticas dos falantes em relação às variedades linguísticas utilizadas na Região Administrativa de Galópolis, pertencente ao Município de Caxias do Sul e situada na Região de Colonização Italiana do Rio Grande do Sul - RCI. As duas comunidades escolhidas para a realização da pesquisa foram a Sede de Galópolis (zona urbana) e a Comunidade de Santo Antão na Terceira Légua (zona rural). Ao observar que na fala dos moradores das duas comunidades havia ocorrências de três variedades linguísticas: português padrão, dialeto italiano e português com interferências do dialeto italiano, a pesquisadora analisou as atitudes linguísticas de prestígio ou desprestígio - preconceito ou estigma - dos falantes em relação às variedades linguísticas existentes nas localidades. O questionário utilizado pela pesquisadora encontra-se em anexo.

Roncarati (2008) aborda a definição de prestígio e de sua contraparte, o preconceito linguístico, baseada na visão laboviana e nos dados da tese de doutorado de Lucia Furtado de Mendonça Cyranka que ela orientou, em 2007: Atitudes lingüísticas de alunos de escolas públicas de Juiz de Fora - MG.

Roncarati (2008, p. 48) salienta que, no âmbito dos estudos sobre mudança linguística, não é possível discutir preconceito e prestígio linguísticos e temas a eles afetos (atitudes, crenças, imaginários linguísticos), sem se levar em conta um dos pilares sustentadores da inquirição sociolinguística sobre a variação e a mudança linguística: o problema da avaliação linguística.

Por seu turno, Cyranka e Roncarati (2009) ressaltam que os professores de língua materna ainda têm dificuldade em incorporar os avanços dos estudos linguísticos as suas práticas de trabalho em sala de aula. E as autoras acrescentam:

Nesse sentido, compreender as atitudes linguísticas, isto é, investigar como os usuários avaliam a variedade utilizada por eles próprios, por seus interlocutores e pela escola, tendo em vista os traços correlacionados com sua posição social, ou ainda com as práticas de oralidade e letramento, pode abrir caminho para, entre outros, possibilitar a otimização da aprendizagem escolar e motivar o desenvolvimento de competências linguísticas, dentro de uma visão mais ecológica no ensino de língua (CYANKA, RONCARATI, 2009: p.20).

Garcia (2009) discute o papel das atitudes linguísticas na manutenção ou não da primeira língua e/ou do bilinguismo em comunidades indígenas bilíngues. A autora analisa algumas das atitudes linguísticas da comunidade Terena de Ipegue, localizada no município de Aquidauana (MS), com a língua de contato (o português). Garcia (2009, p.115) observa que 
os julgamentos negativos da comunidade majoritária para com a língua Terena são interiorizados pela maioria da população de Ipegue. Conforme as entrevistas nos trabalhos de campo, a comunidade Ipegue é vista como mais "civilizada" do que as demais comunidades da mesma reserva, em razão do uso da língua Portuguesa (GARCIA, 2009, p. 115).

Na região de fronteira norte do Brasil, Calvet (2009) e Pereira (2009) analisaram as representações linguísticas da população na fronteira Oiapoque-Saint George, na Guiana Francesa. Os autores já haviam realizado uma pesquisa piloto sobre representação das línguas estrangeiras junto a um público de diferentes universidades no Rio de Janeiro. Calvet (2009) analisa a relação entre margem e periferia a partir da dinâmica linguística naquela região de fronteira, de suas práticas e atitudes linguísticas. Pereira (2009) destaca a inversão do valor das representações em relação às línguas, considerando as diferenças dos contextos investigados, tanto do ponto de vista sociocultural quanto econômico. $\mathrm{O}$ questionário utilizado nas pesquisas foi adaptado posteriormente por Espírito Santo (2009) e Costa (2011), em anexo.

Considerando que os critérios que levam o governo a legislar sobre o ensino de algumas línguas estrangeiras e os que levam as instituições privadas a oferecer outras línguas podem ter alguma relação com as motivações dos estudantes ao optarem por aprender esses idiomas, contudo, essa relação não é obrigatoriamente direta, unilateral ou verdadeira, Costa (2011) realizou uma pesquisa sobre representação linguística sobre as línguas estrangeiras ensinadas em dois colégios de aplicação no Rio de Janeiro (CAp-UERJ e CAp-UFRJ). A autora investigou as seguintes questões: a) Quais são as representações linguísticas dos alunos em relação às línguas estrangeiras? b) Quais são as motivações dos alunos ao escolherem determinada(s) língua(s) estrangeira(s) em sua escola? e c) Qual o peso das políticas linguísticas vigentes nesse processo de escolha?

Silva Junior (2011) investigou o contato linguístico entre a língua portuguesa e a língua tikuna entrecruzando os conceitos de identidade, representações linguísticas e política linguística. Um dos aportes desse trabalho é fornecer subsídios que tornem mais eficazes as práticas pedagógicas para o ensino da língua materna e do português como L2.

Não é o nosso propósito aqui estabelecer uma lista exaustiva sobre os trabalhos que tratam do tema atitude e representação linguística no Brasil. Selecionamos apenas algumas das inúmeras pesquisas com o objetivo de ilustrar a importância do tema para a sociolinguística no país. O Projeto crenças e atitudes linguísticas: um estudo da relação do português com línguas de contato, coordenado pela Prof. ${ }^{a}$ Aparecida FeolaSella e desenvolvida pela Prof ${ }^{a}$ Vanderci de Andrade Aguilera em conjunto com docentes da UNIOESTE, 
UEL, UEPG e UEM, é um bom exemplo para por em evidência a aplicação desse conceito nos estudos linguísticos.

Dentre os objetivos previstos por esse projeto interinstitucional, destacamos: compor um banco de dados orais, compartilhado, relativos à consciência, crença e atitudes linguísticas; descrever a crença e as atitudes linguísticas de falantes; brasileiros naturais de comunidades fronteiriças e de imigração em relação à língua materna, à segunda língua e/ou à língua de contato; analisar dados sobre manifestações linguísticas indicativas da cultura da região de fronteira e de contato; identificar fatores decorrentes da crença linguística que conduzem à atitudes negativas em relação à língua e ao grupo do outro.

Apresentamos, em anexo, alguns dos questionários utilizados nas pesquisas supracitadas para que sirvam de inspiração na definição dos instrumentos de pesquisas de futuros trabalhos envolvendo o tema representação/atitude linguística.

\section{Considerações Finais}

A divulgação de pesquisas relacionadas ao tema atitude ou representação linguística nos permite avançar na compreensão das situações de contato linguístico, de mudanças de código ou alternância de línguas e nos sentimentos de segurança ou insegurança linguística dos falantes. É importante lembrar que no caso das políticas linguísticas voltadas para a manutenção das línguas o seu sucesso depende, entre outros fatores, do prestígio social da língua e de seu grupo de falantes, e que o desaparecimento de uma língua pode estar menos associado à dominação de uma língua que às escolhas feitas pelos falantes em termos de que línguas vão transmitir aos filhos.

Essas pesquisas permitem ainda que os direitos linguísticos dos falantes tenham mais visibilidade e que o Estado cumpra o seu dever ao propor políticas educacionais que promovam o respeito à diversidade linguística.

Como pudemos observar os trabalhos aqui apresentados, dentre tantos outros possivelmente em desenvolvimento, abordam questões pertinentes à linguística tendo como um dos principais fatores de análise as atitudes/representações linguísticas. Em outras palavras, o tema atitude linguística foi relacionado às línguas em contato nas regiões de fronteiras, às línguas de comunidades de imigrantes, às línguas indígenas, ao ensino de língua materna e de línguas estrangeiras.

Essas pesquisas têm ainda o mérito de fazer investigações e coleta de dados a partir de trabalhos de campo. Ora, sabemos que esse tipo de trabalho é fundamental para a formação dos linguistas. Ele permite que conheçamos na prática aquilo que embasa nossas teorias, que tenhamos um contato direto com as comunidades linguísticas pesquisadas, e que tenhamos uma visão 
crítica das situações linguísticas. Além disso, esse tipo de trabalho abre novas perspectivas para outras abordagens que não estavam necessariamente delineadas no início da pesquisa.

Finalmente, tratando-se de um tema imbuído de subjetividade, não basta elencar as representações acerca das línguas em uma dada comunidade; a análise dos dados requer uma visão holística dos fatos, daí a natureza transdisciplinar dos estudos sobre atitudes linguísticas.

\begin{abstract}
When asked about the reasons for studying social representation, Moscovici (2010) answered that it was in order to explore the subjective side of facts of objective reality. In this paper, we propose a literature review concerning the concept of linguistic representations, in the sociolinguistics perspective, since its creation, in the social psychology, to its application to studies of language. We emphasize the notion of linguistic representation as a concept collectively built around a language, characterized by the practice and the discursive memory of its speakers, as well as the ideology in which they belong, emphasizing its importance for the analysis of linguistics dynamics.
\end{abstract}

Keywords:Social representation; linguisticrepresentation; linguisticattitudes

\title{
REFERENNCIAS
}

AGUILERA, V. de A. Crenças e atitudes linguísticas: quem fala a língua brasileira? In: RONCARATTI, C.; SAVEDRA, M. M. G. Português Brasileiro. Rio de Janeiro: Faperj, 2007.

BARBOSA, G. C. Atitudes lingüísticas e identidade na fronteira Brasil-Colômbia. Rio de Janeiro: UFRJ, 139 p. Dissertação de Mestrado. Departamento de Linguística e Filologia, Faculdade de Letras, UFRJ, 2004.

BERGAMASCHI, M.C.Z. Bilinguismo de dialeto italiano-português: atitudes linguísticas. Dissertação apresentada ao Curso de Pós-Graduação em Letras e Cultura Regional da Universidade de Caxias do Sul, 2006.

BRUNETIERE,V.;GUELLOUZ, M. Overture. In.: HOUDEBINE, A-M. De l'imaginaire linguistique a l'imaginaire culturel. Travaux de sémiologie $\mathrm{n}^{\circ}$ 7, p. 7-9, 2008.

CALVET, L-J. Pour une écologie des langues du monde. Paris: Plon, 1999. 
CALVET, L.-J. Oiapoque /Saint-Georges de l'Oyapoque: effets de marge et fusion des marges en situation frontalière In Bulot, $\mathrm{T}$ (org.) Formes et Normes sociolinguistique Ségrégations et discriminations urbaines. Paris : L'Harmattan, p. 15-40, 2009.

CALVET, L-J. Langues et développement: agir sur les représentations? In: Estudios de sociolingüística 1(1), p. 183-190, 2000.

CANUT, C. Imaginaires linguistiques en Afrique. Paris, L'Harmattan. 1998.

CASTELLOTTI, V; MOORE, D. Représentations sociales des langues et enseignements. Conseil de l'Europe: Strasbourg, 2002.

CAVALLI, M.; COLETTA, D. Langues, bilinguismes et représentations sociales au Val d'Aoste. Aoste. IRREVDA, 2003.

COSTA, D. Representações linguísticas de alunos de Ensino Médio na aprendizagem de lingua estrangeira. Dissertação de mestrado apresentada ao programa de Pós-Graduação em Estudos de Linguagem da Universidade Federal Fluminense, UFF, 2011.

CYRANKA, L. F.M e RONCARATI, C. Atitudes linguísticas: uma pesquisa em escolas públicas de Juiz de Fora (MG -Brasil). Trabalho apresentado no VI Congresso Internacional da ABRALIN, mar. 2009. Disponível em:

http://www.ufjf.br/fale/files/2010/06/Atitudes-lingu\%C3\%ADsticas-uma-pesquisa-em-escolas-p\%C3\%BAblicas-de-Juiz-de-Fora-Revista-Diacr\%C3\%ADtica.pdf

DURKHEIM, E. As regras do método sociológico. In: Durkheim, vida e obra (Os pensadores). São Paulo: Abril Cultural, 1973.

ESPIRITO SANTO, M.M. De Oiapoque a Saint-Georges: uma pesquisa sociolinguística em meio escolar na fronteira Brasil e Guiana Francesa. Dissertação de mestrado apresentada ao Programa de Pós-graduação em Letras da Pontifícia Universidade Católica do Rio de Janeiro - Puc-Rio. 2009.

FASOLD, R. Introduction to Sociolinguistics. Oxford: Blackwell Publishers limited, 1984.

FISHMAN, J. Sociología del Lenguaje.Madrid: Cátedra, 1995.

FIGUEIREDO, S. E. A. Atitudes de estudantes brasileiros diante de falantes de alemão, espanhol, francês, inglês e português. Campinas, 2003. Dissertação de mestrado apresentada ao Instituto de Estudos da Linguagem, Universidade Estadual de Campinas, 2003.

GARCIA, M.S. O papel das atitudes linguísticas na manutenção ou não da língua indígena em comunidades indígenas bilíngues: o caso ipegue/terena. Revista Eletrônica Via Litterae - ISSN 2176-6800. Via Litterae, Anápolis, v. 1, n. 1, p. 99-118, jul./dez. 2009.

HOUDEBINE-GRAVAUD, A-M. Théorie de l'imaginaire linguistique: de l'imaginaire linguistique á l'imaginaire culturel et modélisation. Sêmeion 7. RevuedulaboratoireDynaLang-SEM. Université Paris Descartes, 2008. 
JODELET, D. As representações sociais. Rio de Janeiro: Eduerj, 2001. LAFONTAINE, D. Attitudes linguistiques. In : Marie-Louise MOREAU (éd) Sociolinguistique, concepts de base, Sprimont, Mardaga, p. 56-60, 1997.

LAMBERT, W. E., HODGSON, R. C., GARDNER, R.C., FILLENBAUM, C. Evaluation reactions to spoken language.Journal of Abnormal and Social Psychology60, p. 44-51, 1960,

LEGLISE, I; MIGGE, B. Pratiques et représentations linguistiques em Guyane: regards croisés. Paris: IRD Éditions, 2007.

MARIANI, B. Colonização linguística; línguas, política e religião (Brasil, sécs. XVI a XVIII e Estados Unidos da América, século XVIII). Campinas, Pontes, 2004.

MELLO, H. Atitudes linguísticas de adolescentes americano-brasileiros de uma comunidade bilíngue no interior de Goiás. In: Revista Letras, PUC-Campinas, v. 22 (1/1), p. 85-114, dez. 2003,

MOREAU, M.-L. Sociolinguistique, concepts de base. Sprimont: Mardaga, 1997.

MORENO FERNÁNDEZ, F. Princípios de Sociolingüística y sociologíadellenguaje. Barcelona: Ariel, 1998.

MOSCOVICI, S. La Psychanalyse, son image et son public. Paris: Presses Universitaires de France.1961

MOSCOVICI, S. Representações sociais. Investigações em psicologia social. $7^{\text {a }}$ ed. Vozes, 2010.

OLIVEIRA, G. M. As línguas minoritárias e a gestão descentralizada de políticas linguísticas: reflexões sobre o caso brasileiro. II Seminário Interamericano sobre Gestão das Línguas, Assunção, 2003. Disponível em <www.ipol.org.br>

PEREIRA, T. Representação e aprendizagem de uma língua estrangeira: status da língua francesa em contexto urbano e de fronteira. In: Synergies Brésil. São Paulo: GERFLINT, p. 101-112, 2009.

PETITJEAN, C. Représentations linguistiques et plurilinguisme. Thèse de doctorat des Université de Provence et de Neuchâtel, spécialité Sciences du langage, 2009. Disponível em:

http://doc.rero.ch/lm.php?url=1000,40,4,20100224121740-CN/ Th_Petitjean.pdf

RIBEIRO, I. Atitudes linguísticas e aprendizagem de línguas: um estudo de caso em Foz do Iguaçu. Dissertação apresentada ao Programa de Pós-Graduação Stricto Sensu da Universidade Estadual do Oeste do Paraná. UNIOESTE, 2007.

RONCARATI, C. Prestígio e preconceito linguísticos. Cadernos de Letras da UFF - Dossiê: Preconceito linguístico e cânone literário, no36, p. 45-56, 2008.

SILVA JUNIOR, E.S. Identidade, representação linguística e educação bilingue: um estudo sociolinguístico em situação de contato portu- 
guês-tikuna. Dissertação de mestrado apresentada ao programa de Pós-Graduação em Estudos de Linguagem da Universidade Federal Fluminense, UFF, 2011.

\section{ANEXOS}

\section{Questionário utilizado por M. C. Z BERGAMASCHI (2006)}

\section{Atitudes linguísticas}

Concordo plenamente -concordo -nem concordo nem discordo- discordo - discordo totalmente

1. Esta pessoa que você ouviu é inteligente

2. Esta pessoa que você ouviu é feia.

3. Esta pessoa que você ouviu sente vergonha de falar assim.

4. Esta pessoa que você ouviu é estudada.

5. Esta pessoa que você ouviu sofre preconceito social.

6. Esta pessoa que você ouviu sente orgulho de falar assim.

7. Esta pessoa que você ouviu é atrasada.

8. Esta pessoa que você ouviu é grossa.

9. Esta pessoa que você ouviu é trabalhadora.

10. Esta pessoa que você ouviu é um típico morador da colônia.

11. Esta pessoa que você ouviu vive na cidade.

12. Esta pessoa que você ouviu segue a igreja católica, é praticante e temente a Deus.

13. Esta pessoa que você ouviu tem respeito à família, aos pais e irmãos mais velhos.

14. Esta pessoa que você ouviu foi orientada a trabalhar.

15. Esta pessoa que você ouviu dá importância ao trabalho como forma de vencer na vida.

16. Esta pessoa que você ouviu ajuda os outros quando precisam.

17. Esta pessoa que você ouviu engana os outros.

18. Esta pessoa que você ouviu dá valor aos ensinamentos dos pais.

19. Esta pessoa que você ouviu é de confiança.

20. Esta pessoa que você ouviu exerce a profissão de 
2. Questionário proposto por: V. A. AGUILERA (2007)

PROJETO CRENÇAS E ATITUDES LINGÜÍSTICAS:

UM ESTUDO DA RELAÇÃO DO PORTUGUÊS COM LÍNGUAS DE CONTATO

Entrevistadora: Data:

Informante: $\mathrm{n}^{\mathrm{o}}$ Idade: anos

Escolaridade:

Natural de

Veio para M. C. Rondon com anos.

Naturalidade dos pais:

1. - Que língua você fala?

2. - Quando você era criança, em que língua seus pais falavam com você?

3. - Quando você era criança, em que língua seus avós falavam com você?

4. - Quando você era criança, em que língua você falava com seus pais e avós?

5. - Aqui em Marechal Rondon existem pessoas que falam diferente de você?

6. - Que língua(s) fala(m) os que falam diferente aqui? (espanhol argentino, espanhol paraguaio, italiano, alemão).

7. Poderia dar um exemplo do espanhol argentino?

8. - Poderia dar um exemplo do espanhol paraguaio?

9. - Poderia dar um exemplo do alemão?

10. - Poderia dar um exemplo do italiano?

11. - Comparando essas línguas: argentino, paraguaio, italiano e alemão, quem fala melhor? Por quê?

12. - E quem fala pior? Por quê?

13. - Em que lugares você ouve esta(s) língua(s) ou modo(s) de falar diferente(s)?

14. Quando você se aproxima dos paraguaios, eles costumam parar de conversar entre eles, ou continuam?

15. E os argentinos, costumam parar de conversar entre eles, ou continuam?

16. E os alemães, costumam parar de conversar entre eles, ou continuam?

17. E os italianos, costumam parar de conversar entre eles, ou continuam?

18. Falam melhor os que falam o português ou os que falam essas línguas estrangeiras de que falamos?

19. Essas línguas são feias ou bonitas? 
20. Qual é a mais bonita?

21. E a mais feia?

22. Você acha que deveria ser proibido o uso dessas línguas em lugares públicos aqui em Marechal Rondon?

23. Na igreja ou no templo, o sacerdote, pastor ou palestrante deveria falar também

nessa(s) língua(s)? Em qual / quais delas? Por quê?

24. A escola deveria ensinar essas línguas que você ouve aqui? Qual delas? Por quê?

25. Você gostaria de aprender a falar alguma dessas línguas estrangeiras faladas aqui? Qual delas? Por quê?

26. Você estudou ou fala alguma dessas línguas? Qual? Onde aprendeu?

27. Se você fosse comprar uma casa num bairro onde só morassem argentinos, você compraria?

28. E se lá só morassem paraguaios, você compraria?

29. E se lá só morassem alemães, você compraria assim mesmo?

30. E se lá morassem apenas italianos, você compraria assim mesmo?

31. Você tem amigos argentinos? Como começou esta amizade?

32. Você tem amigos paraguaios? Como começou esta amizade?

33. E amigos alemães? Como começou esta amizade?

34. E amigos italianos? Como começou esta amizade?

35. Com qual deles você sente que a amizade é mais sincera? Por quê?

36. Com qual deles você sente que a amizade é falsa ou interesseira? Por quê?

37. Você já teve algum desentendimento ou briga com algum deles? Por que

motivo?

38. Você namoraria ou se casaria com um(a) argentino (a)? Por quê?

39. E com um(a) paraguaio (a)? Por quê?

40. E com um(a) alemão (ã) Por quê?

41. E com um(a) italiano (a)? Por quê?

42. Se precisasse de um médico ou dentista procuraria um argentino? Por quê? 
43. E um médico ou dentista paraguaio? Por quê?

44. E um médico ou dentista alemão? Por quê?

45. E um médico ou dentista italiano? Por quê?

46. Sobre essa multiplicidade de línguas que você ouve aqui em Marechal Rondon,

gostaria de falar mais alguma coisa que eu não tenha perguntado?

47. Você permite que eu use em meu trabalho o que falamos aqui?

3. Questionário utilizado por: T.PEREIRA (2009)

Questionário sociolinguístico

Escola Série

Data

Sexo: ( ) feminino ( ) masculino

Lugar de nascimento:

Do aluno

Do pai

Da mãe

Outro responsável

Qual a língua materna :

Do aluno

Do pai

Da mãe

Outro responsável

4. Em que língua ( $\mathrm{s}$ ) você(s) fala(am):

Em casa

Com amigos

No comércio

Se você fala mais de uma língua, em que circunstância você aprendeu a outra língua?

Em casa, você tem acesso a jornais, revistas e a programa de TV e rádio em que línguas?
( ) Francês
( ) Português
( ) Patuá
( ) Espanhol
( ) Inglês
( ) Crioulo 
Quais línguas você estuda na escola?

Quais línguas você gostaria de aprender? Por quê?

Quais língua(s) você acha mais bonita?

Quais língua(s) você acha mais útil?

Quais língua(s) você acha mais fácil?

Quais línguas você considera mais difícil?

Além do português, quais língua(s) são faladas no Brasil?

Há regiões no Brasil em que se fale mais de uma língua?

Quais regiões?

.Que línguas são faladas na América do Sul?

4. Questionário utilizado por D. COSTA (2011)

Enquete sociolinguística

Alunos do $1^{\circ}$ Ano do Ensino Médio dos CAp

Escola:

Sexo: $\mathrm{M}($ ) $\mathrm{F}($ )

Idade: Nacionalidade

Do aluno

Do pai do aluno

Da mãe do aluno

Naturalidade

Do aluno

Do pai do aluno:

Da mãe do aluno:

Bairro onde mora:

1. Quais línguas estrangeiras você estudou na escola?

( ) alemão ( ) espanhol ( ) francês ( ) inglês ( ) italiano

() outras:

2. Quais línguas estrangeiras você estuda atualmente na escola?

( ) alemão ( ) espanhol ( ) francês ( ) inglês ( ) italiano

() outras: 
3. Por que você optou por essa língua estrangeira no Ensino Médio?

4. Você estuda alguma língua estrangeira fora da escola? Qual?

5. Você gostaria de aprender outras línguas estrangeiras? quais?

6. Qual língua você acha mais bonita?

7. Qual língua você acha mais útil?

8. Qual língua você acha mais fácil?

9. Qual língua você acha mais difícil?

10. Além do português, quais línguas são faladas no Brasil?

11. Que línguas são faladas na América do Sul?

12. Que idiomas você costuma utilizar nas seguintes situações:

- redes sociais:

- pesquisas escolares:

- programas de TV:

- ouvir música:

- viagens:

- entre familiares e amigos: 